\title{
Análisis
}

\section{Daisy: un libro digital abierto, multimodal y accesible}

\author{
Por Mireia Ribera y Santi Moese
}

\begin{abstract}
Resumen: Se presenta el formato de libro multimedia Daisy que permite integrar texto, sonido, imágenes y vídeo de forma sincronizada y con una navegación avanzada por el texto y el audio que lo hace altamente usable para lecturas en digital. También se presenta su componente principal DTBook xml, disposición estructurada del texto que permite generar formatos alternativos. El artículo detalla las diferencias de Daisy respecto a otros audiolibros, los dispositivos de lectura existentes y su adopción en el mercado y en la enseñanza. Si se abaratan los costes de los aparatos lectores y se soluciona la gestión de derechos digitales, tiene muchas posibilidades de convertirse en estrella para editar libros digitales.
\end{abstract}

Palabras clave: Daisy, Audiolibros, DTBook, Formatos alternativos, Lectura digital, Accesibilidad digital.

Title: Daisy: an open, multimodal and accessible digital book

Abstract: Introduction of the Daisy multimedia book format, which integrates text, sound, images and video in a synchronized sequence. Daisy presents a high usability for digital reading thanks to its advanced navigation through text or audio. The article also describes DTBook, the text component of Daisy, which is a highly

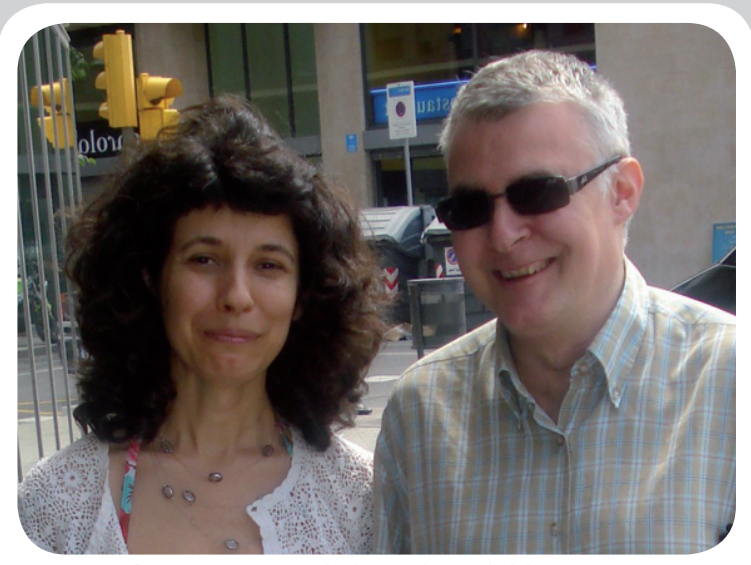

Mireia Ribera Turró, es diplomada en biblioteconomía e ingeniera informática. Trabaja en el campo de la accesibilidad y ha analizado la accesibilidad de html y pdf. Actualmente está elaborando su tesis sobre el formato Daisy.

Santi Moese Ruiz, filólogo de formación y ciego de nacimiento, es formador en ayudas técnicas en la ONCE en Barcelona y Gerona. Es responsable de instalar puestos de trabajo y de estudio accesibles y de resolver dudas tecnológicas de sus usuarios. structured xml format ideal to create alternate format editions.

The article sets out the differences between Daisy and other audiobooks and presents the most common Daisy players and Daisy market adoption. The format has good potential for becoming a flagship format in ebook publishing if costs of playing devices decrease and a solution is found for digital rights management.

Keywords: Daisy, Audiobooks, DTBook, Alternative formats, Digital reading, Digital accessibility.

Ribera, Mireia; Moese, Santi. “Daisy: un libro digital abierto, multimodal y accesible". En: El profesional de la información, 2008, julio-agosto, v. 17, n. 4, pp. 403-407.

DOI: 10.3145/epi.2008.jul.05

\section{Introducción'}

CON LA APARICIÓN DE MÚLTIPLES DISPOSITIVOS INFORMÁTICOS con suficiente memoria y capacidad de procesamiento, el audio se ha convertido -de nuevo, como en los tiempos anteriores a la televisión- en un relevante canal de comunicación.

Apple ofrece audiolibros en su plataforma iTunes, Amazon ha comprado Brilliance Audio y Audible (editores de audiobooks) y ha creado el lector Kindle para libros electrónicos con soporte audio.
Nokia ofrece audiobooks para sus clientes, etc. Incluso revistas científicas consolidadas como Nature o Science publican podcasts semanales con novedades en sus respectivas áreas. En EUA la American Publishers Association ha lanzado la campaña "Get caught listening" 2 para difundir el placer de este tipo de lectura. La tendencia creciente (Peters, 2007) tiene un claro reflejo en la venta de audiolibros. Los informes de ventas de la Asociación de Editores de Audio demuestran esta tendencia: en 2006 las ventas aumentaron un 4,7\%; en 2007 un
6\% (Audio Publishers Association, 2007). Aun así la oferta comercial es limitada y suele incluir sólo bestsellers.

Daisy (Digital access to information system) es un formato digital que puede incluir texto, sonido, imágenes y vídeo integrados en una misma secuencia temporal gracias a ficheros smil (synchronized multimedia integration language). A diferencia de otros formatos de libro electrónico, ofrece posibilidades avanzadas de lectura como saltar por capítulos, por secciones, por 
páginas o incluso por frases, añadir puntos de libro y anotaciones por parte del lector. Estas opciones se suelen ofrecer en texto y también en audio, lo que representa una gran ventaja para personas ciegas o con deficiencias visuales, o para situaciones con mala iluminación, conducción o lectura mientras se realizan otras actividades.

Daisy está pensado para una gran diversidad de usuarios: creado inicialmente para personas ciegas puede ser de mucha ayuda para las que tienen poca visión (una gran mayoría de nuestros mayores); para disléxicos (de los que hay un gran número en nuestras universidades) y evidentemente para situaciones varias, como en el metro, haciendo deporte, etc.

\section{"Daisy está pensado para invidentes, personas con visión disminuida, con dislexia o para situaciones discapacitantes como mala iluminación o conducción"}

Una de las grandes diferencias de las grabaciones Daisy existentes frente a los audiolibros comerciales mayoritarios es el estilo de locución. En estos últimos la locución suele ser dramatizada: se usan diferentes voces para distintos personajes, se incluye música y sonidos de fondo, se interpretan llantos, risas, y diferentes emociones, de forma parecida a las antiguas series de radio. En la mayoría de libros Daisy realizados por locutores, la lectura suele ser transparente: se usa una única voz para todo el texto, la expresión es neutra y no se incluyen música ni efectos especiales.

Otra gran diferencia es que los audiolibros comerciales suelen ser versiones adaptadas y abreviadas; en cambio, los libros Daisy son completos y muy fidedignos a los originales (incluyendo una audiodescripción de gráficos u otro material cuando se considera necesario).

Estas diferencias responden a los objetivos y a los usuarios de ambos productos: los de Daisy son más bien personas con baja visión, para los cuales Daisy es el único medio de lectura. La locución neutra y la fidelidad al original permiten una experiencia lectora rica y personal, creando cada lector su propia interpretación del texto. En cambio los audiolibros se venden como alternativa a la lectura en papel para personas ordinarias que, al no estar acostumbradas a una atención sostenida por el oído, perderían rápidamente su concentración si los audiolibros no estuvieran enriquecidos con personajes, dramatización, etc.

\section{Orígen del formato}

Daisy nació en la Biblioteca Nacional de Suecia el año $1988^{3}$, en una investigación sobre alternativas a los cassettes audio para ciegos, cuyo principal inconveniente era su baja usabilidad.

El primer prototipo se presentó en la International Conference on Computers Helping People en 1994 $\mathrm{y}$, debido a un creciente interés internacional en los libros hablados, en 1995 diversas compañías e instituciones organizaron una reunión en Toronto para hablar de una estrategia común. De esta forma, una compañía japonesa presentó sus ideas para desarrollar un lector Daisy.

A iniciativa de la biblioteca nacional de Suecia, en 1996 se creó el Consorcio Daisy ${ }^{4}$ de ámbito internacional para promover la difusión del formato tanto para personas con problemas de lectura como para audiolibros comerciales. A través del Consorcio se logró aprobar la norma NISO Z39.86 que lo regulaba.
Actualmente está en vías de publicación su tercera versión.

\section{Dispositivos de lectura}

Para leer un libro Daisy podemos usar un aparato lector específico, como Victor Reader, de $\mathrm{Hu}$ manWare que acepta cds, o como Milestone, de Bones, que ya trabaja con memorias electrónicas. También se puede usar software para microordenadores como AMIS (Sistema de información multimedia accesible) desarrollado en el marco del proyecto Daisy for all, gratuito y traducido al español por el Centro de Investigación y Desarrollo en Aplicaciones Tiflotécnicas, de la ONCE; o EasyReader, de Dolphin, un lector comercial.

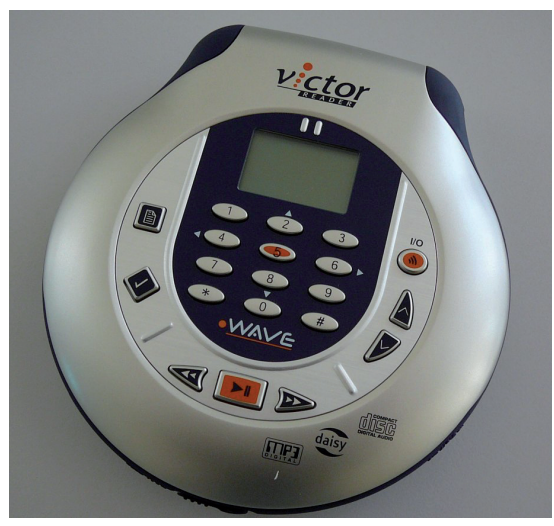

Figura 1. Victor Reader

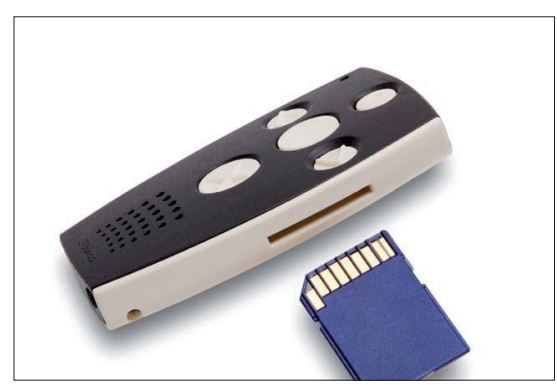

Figura 2. Victor Reader

Los lectores portables suelen ofrecer únicamente soporte para la consulta de audio y tienen precios elevados (entre 2 y 3 veces el de un iPod Nano).

Los lectores software deben poder gestionar ficheros smil (existen muchos programas y también ex- 


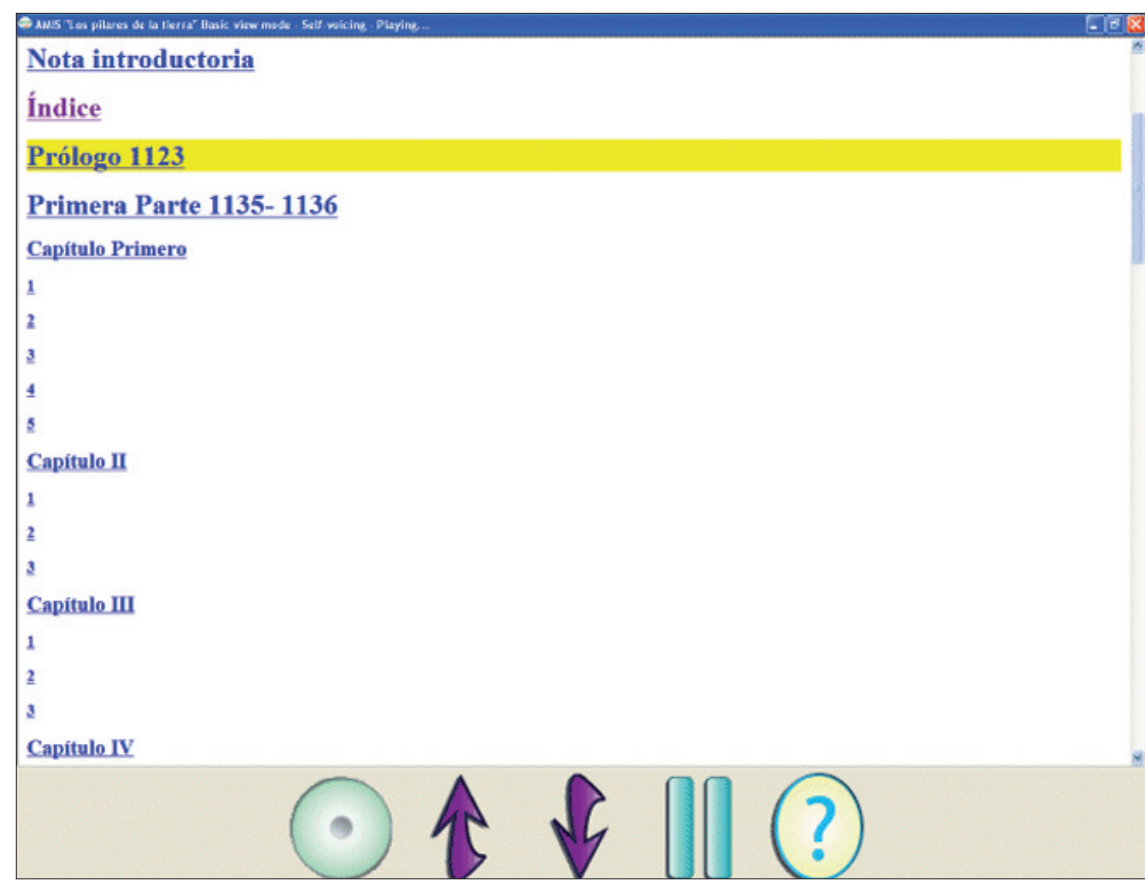

Figura 3. AMIS

tensiones para Firefox que lo permiten) y además incluir controles de navegación de avance, retroceso, cambio de nivel de jerarquía, etc., aunque existen varios lectores software Daisy gratuitos. La mayoría incluye soporte para audio y para texto; algunos comerciales también permiten leer imágenes y actualmente sólo el citado EasyReader de Dolphin lo ofrece para vídeos (NCAM, 2006).

\section{Descripción técnica}

Daisy es el formato final de una familia de subproductos del $D T$ Book, un formato xml que aparece como pilar para la edición de documentos alternativos. Xml DTBo$o k$ (ANSI, NISO) es un xml para el texto de un libro Daisy parecido al DocBook (Oasis) pero en el que se especifica un nivel mayor de granularidad del contenido del libro. DTBook permite indicar las frases, seis niveles de encabezados, tablas y, en sus versiones más recientes, aprovecha la extensibilidad de xml para incluir el lenguaje Mathml para fórmulas matemáticas.

DTBook es el formato origen para crear libros Daisy digitales de forma automática (mediante sinte- tizadores de voz), libros con texto ampliado en pdf, libros html accesibles, y en Braille a través de cadenas de transformaciones xml.

\section{"Daisy es el formato} final de una familia de subproductos del DTBook, que aparece como pilar para la edición de documentos alternativos tales como html accesible, Braille o pdf con tipografía ampliada"

Existen 6 variantes de documentos Daisy:

- Audio con sólo título: vendría a ser como un $m p 3$. No ofrece navegación ni ninguna de las ventajas del formato.

- Audio con sumario: es la variante más común e ideal para los lectores portables. Es la utilizada por la $O N C E$ y permite navegación por el contenido, pero no búsquedas por texto.
- Audio con sumario y parte del texto: parecida a la anterior, incluye el texto del índice, glosario, etc., para permitir búsquedas.

- Audio y texto completo: es la variante más compleja pero que provee el mejor nivel de acceso. A menudo es el resultado de un procesado automático con voz sintetizada a partir de un texto electrónico en formato Word u $O D F$.

- Texto completo y parte de audio: muy inusual. El audio se aplica a las partes en las que la pronunciación es importante, como por ejemplo un diccionario.

- Texto sin audio: contiene sólo la parte textual estructurada según DTBook. Se usa como base para crear Daisys completos u otros formatos alternativos.

En ellos la información de un documento Daisy se organiza de la siguiente manera:

- Un identificador único como libro digital.

- Metadatos bibliográficos (Dublin core) y técnicos (formato propio).

- Un sumario digital en html de las diferentes partes del libro. Hace referencia a los ficheros smil que sincronizan el resto del contenido.

- Una guía, con referencias directas al sumario, bibliografía y prólogo.

Como formato textual el único aceptado es DTBook, es decir texto plano marcado estructuralmente con esta definición de tipo de documento de xml. Como sonido se aceptan ficheros $m p 4, m p 3$ (el más común), o wav. Las imágenes pueden ser jpg, png o svg. El formato de los vídeos no está explicitado.

\section{Adopción}

Aunque hasta aquí hemos hablado de las bondades técnicas, como sabemos, el éxito de un producto 
en el mercado no sólo depende de factores técnicos, sino que su adopción por la industria es determinante para su difusión (recordemos el conocido caso de los sistemas Beta y $V H S$ de vídeo doméstico). En este sentido Daisy goza de un alto grado de adopción: Microsoft lanzó en noviembre de 2007 una extensión a su editor de textos Word (aún en fase beta) para transformar un documento .doc a DTBook 5 , y Open Office lanzó el 23 de mayo de 2008 una extensión similar ${ }^{6}$. El IDPF (International Digital Publication Forum) ha adoptado DTBook y otras partes de Daisy como obligatorios para todo el resto de libros electrónicos para garantizar la interoperatividad de los contenidos (Gylling, 2007). La Library of Congress ha puesto en marcha un programa "talking books" para servir documentos impresos a personas mayores y con dificultades de lectura, con la previsión de publicar 80.000 libros en formato Daisy. Y es que detrás de todo está el Consorcio Daisy, que lo impulsa en el mundo entero.

En Francia y España Braillenet y $O N C E$ respectivamente lo han adoptado como base para su colección de libros para personas ciegas. La ONCE trabaja con locutores profesionales para grabar el audio de sus libros y darles mejor calidad. Actualmente cuenta ya con una biblioteca de unos 15.000 libros Daisy. Braillenet ha desarrollado una cadena de transformaciones $X S L$, parte de las cuales se pueden experimentar en Euain ${ }^{7}$.

\section{Daisy en la enseñanza}

El área de la educación primaria y secundaria es una de las más activas en la promoción de este formato, pues si los editores incorporan Daisy en su cadena de producción resulta mucho más fácil, rápido y barato poder crear versiones alternativas para estudiantes con dificultades para leer.

En EUA el gobierno federal obliga a todos los editores de libros de texto de primaria y secundaria a crear una versión de sus publicaciones siguiendo la norma Nimas ( $\mathrm{Na}$ tional instructional material accessibility standard), que no es más que un Daisy simplificado. Se debe vender al mismo precio que la publicación en papel, para uso exclusivo de personas con discapacidad $\mathrm{y}$, a partir de este $\mathrm{xml}$, las escuelas e institutos pueden crear materiales adaptados para sus alumnos. Ello permite que los usuarios con discapacidades puedan satisfacer su derecho al acceso a los recursos educativos curriculares en un formato alternativo según sus necesidades y en un tiempo razonable.

\section{"El gobierno federal de EUA obliga a todos los editores de libros de texto a crear una versión en Daisy simplificado"}

La Universitat Oberta de Catalunya (UOC) ha reeditado todos sus libros en formato DTBook y ha puesto en marcha el programa MyWay (Almirall; Garreta; Rivera, 2006) para que todos sus alumnos se beneficien de la multimodalidad del formato. Este proyecto ha ganado un Gold award de IMS Learning en su edición $2008^{8}$.

\section{Conclusiones}

Son muchos los factores que prometen grandes oportunidades para el formato Daisy:

- Rápido desarrollo que ha permitido que desde su nacimiento, hace sólo 20 años, haya sido adoptado internacionalmente, soportado por un estándar de iure, y convertido en un estándar de facto para libros hablados accesibles.

- Ventajas técnicas, navegación, multimodalidad, y orientación a una amplia capa de la población: personas ciegas o con baja visión pero también personas con dificultades de motricidad o dislexia que no pueden leer libros impresos cómodamente.

- Tendencia general de aumento de producción audio y de consulta de materiales en los entornos más variados (Weiser, 1991), y aparición de aparatos reproductores potentes y con gran capacidad de memoria, así como la generalización de los audiolibros dentro de diversas capas de la población.

\section{"Editores y bibliotecarios deben tomarlo seriamente en consideración para sus planes futuros de edición o digitalización"}

Pero no todo son buenas noticias. Daisy, como integrante de la publicación digital, sufre por la falta de una gestión eficiente de los derechos digitales. El consorcio Daisy tiene como tema de debate prioritario para este año solucionar el DRM (digital rights management) para conseguir respetar los derechos de autores y editores a la vez que no perjudicar la accesibilidad del contenido.

Si se superan algunos obstáculos en los precios y capacidades de los aparatos lectores y en la gestión de los derechos digitales Daisy tiene muchas posibilidades de convertirse en un formato muy importante en el mundo digital.

En cualquier caso ya ha sido demostrada su utilidad como formato de contenido, punto de partida de documentos html, pdf, mp3 y Braille (Guillon, 2004). Editoriales y bibliotecas deben tomarlo seriamente en consideración para sus planes futuros de edición o digitalización (Tank; Frederiksen, 2007). 


\section{Notas}

1. Este artículo es una reelaboración ampliada de la presentación "Una visió de futur: Daisy com a format estrella per a documents digitals" en las 11as Jornadas catalanas de información y documentación (Ribera; Moese, 2008).

2. http://www.getcaughtreading.org /listening

3. http://www.tpb.selenglish/talking_books/his tory_of_daisy/

4. http://www.daisy.org

5. http://www.microsoft.com/presspass/ press/2007/nov07/11-13DAISYPR.mspx

6. http://extensions.services.openoffice.org/pro ject/odt 2 dtbook

7. http://www.euain.org/?q=node/6

8. http://www.ims global.org/pressreleases/ pr080515.html

\section{Bibliografía}

Almirall, Magí; Garreta, Manel; Rivera, Josep. "Made-to-measure learning materials". En: 1st European conference on technology enhanced learning, p. 20.
ANSI/NISO. "Z39.86-2005: specifications for the digital talking book". Consultado en: 15-06-08. http://www.docbook.org/specs/docbook-4.5-spec.html

Audio Publishers Association. "Americans are tuning in to audio: audiobook sales on the rise nationally". Consultado en: 15-06-08.

http://www.audiopub.org/PDFs/2007Sales Surveyrelease.pdf

Guillon, Benoît. "Towards an integrated publishing chain for accessible multimodal documents". En: Lecture notes in computer science, 2004, n. 3.118 , pp. 514-521

Gylling, Markus. "Convergence between the needs of e-accessibility and the constrains of the e-book industry". En: 2nd European eAccessibility forum, 2008.

NCAM. "Beyond the text: comparison chart of ebook and digital talking book (DTB) hardware and software". Consultado en: 15-06-08.

http://ncam.wgbh.org/ebooks/comparison.html

Oasis. "The DocBook document type". Consul tado en: 15-06-08.

http://www.niso.org/workrooms/daisy/Z39-862005.html

Peters, Thomas A. "Digital audiobook services through libraries". En: Library technology reports, ene-feb, 2007, v. 43, n. 1.
Ribera, Mireia; Moese, Santi. "Una visió de futur: Daisy com a format estrella per a documents digitals". En: 11es Jornades catalanes d'informació i documentació, 2008.

Tank, Elsebeth; Frederiksen, Carsten. "The Daisy standard: entering the global virtual library". En: Library trends, 2007, Spring, v. 55, n. 4, pp. 932-949.

Weiser, Mark. "The computer for the twentyfirst century”. En: Scientific American, 1991, pp. 94-104.

Mireia Ribera, Departamento de Biblioteconomía y Documentación,

Melcior de Palau, 140

08014 Barcelona

ribera@ub.edu

http://bd.ub.es/pub/ribera

Santi Moese, Unidad de Tiflotecnología, Organización Nacional de Ciegos de España, Sepúlveda 1; 08015 Barcelona.

smr@once.es

\section{Máster Oficial Universitario Contenidos y Aspectos Legales en la Sociedad de la Información}

\section{Objetivos}

Especializar a profesionales de la información en la gestión de contenidos a través de diferentes plataformas para todos los ámbitos de la sociedad. Ahondar y ampliar los conocimientos en Archivística, Biblioteconomía y Documentación con un enfoque dirigido a la aplicación de las tecnologías de la información en sus nuevos canales. Temas centrales son los contenidos audiovisuales.

\section{Especialidades}

- Información y Documentación: Gestión de contenidos multicanal.

Gestión de contenidos en nuevos formatos y distribuidos por distintos canales. Web 2.0, Redes sociales y Conocimiento colaborativo.

- E-Consulting en sociedad de la información. Planificación de sistemas de información, conocimiento de los procesos informativos en las organizaciones y de los contenidos y su distribución.

- Archivos y administración electrónica

Gestión de los documentos electrónicos y sistemas de gestión documental. Administración electrónica.

\section{Estructura del Máster}

75 ECTS a impartir en un curso académico.

Horario de tarde

Materias- 42,5 ECTS - se compone de asignaturas comunes y asignaturas de la especialidad que se escoja

Asignaturas de libre configuración curricular: 17,5 ECTS

Tesina fin de Máster:

15 ECTS

\section{Profesorado}

Este Máster será impartido por profesorado de diversas Universidades Nacionales así como profesionales de reconocido prestigio.

\section{Fechas}

Plazos de preinscripción:

Del 2 al 12 de Septiembre y del 1 al 8 de Octubre Plazos de Matrícula:

Del 23 al 30 de Septiembre

Del 20 al 24 de Octubre

\section{Información}

Secretaría del Departamento de Comunicación Audiovisual, Documentación e Historia del Arte

(DCADHA) de la UPV.

Teléfono: 963877390

e-mail: dephar@upvnet.upv.es

Página Web:

http://www.upv.es/contenidos/PO/menu_494 351c.html

\section{Preinscripción}

http://www.upv.es/contenidos/PO/menu_49503 5c.html

Estos estudios dan acceso al programa de Doctorado

El master admite estudiantes titulados, tanto de nivel superior como de nivel medio (licenciados y diplomados)

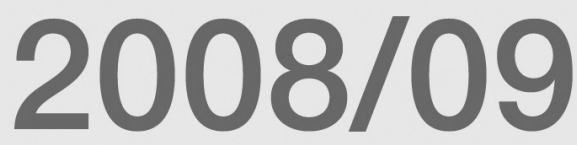

